REGE

29,1

Received 26 February 2021 Revised 3 June 2021 26 July 2021

Accepted 29 July 2021

\section{The factors influencing technological entrepreneurship in nanotechnology businesses}

\author{
Tayebeh Nikraftar \\ Entrepreneurship Faculty, University of Tehran, Tehran, Iran \\ Elahe Hosseini \\ Yazd University, Yazd, Iran, and \\ Elham Mohammadi \\ University of Tehran, Tehran, Iran
}

\begin{abstract}
Purpose - Technological entrepreneurship has been a very significant topic in recent decades. It has a crucial role in economic modernization and growth. The need for technological entrepreneurship is because technology-based industries are expanding rapidly and are replacing traditional industries. Therefore, this study aimed at identifying the factors affecting the success of technological entrepreneurship in Iranian nanotechnology businesses.

Design/methodology/approach - The research was conducted through mixed method. The participants in the qualitative section included 17 university experts and executive managers in the field of nanotechnology in Iran, and 75 nanotechnology business managers participated in the quantitative section. The interview and questionnaire were used to collect information. In order to measure and fit the models, the confirmatory factor analysis method and PLS3 software were used.

Findings - The results indicated that the key factors affecting the success of the technological entrepreneurship process in nanotechnology were classified into five general categories: organizational, environmental, institutional, individual and technology factors. Moreover, it was shown that all these dimensions had a positive and significant effect on technological entrepreneurship. In addition, the organizational dimension has an essential role.

Originality/value - Companies' ability to engage technological entrepreneurship is a vital factor in human resource management and strategic management. However, technological entrepreneurship in Iranian nanotechnology businesses has not been involved integrally in the context of companies.
\end{abstract}

Keywords Entrepreneurship, Nanotechnology businesses, Technological entrepreneurship, Iran Paper type Research paper

\section{Introduction}

Several researchers have focused on the concept of "entrepreneurship" to maintain and improve the sustainability indicators of competitive advantage in organizations and businesses (Tajeddini, 2010). Entrepreneurship is recognized as an essential factor in the enhancement of the economic situation by creating new employment and income opportunities (Chitsaz, Tajpour, Hosseini, Khorram \& Zorrieh, 2019; Sabokro, Tajpour \& Hosseini, 2018). Furthermore, entrepreneurs who are aware of their acquired knowledge and experience can seize business opportunities that often result from extensive knowledge of specific industries, specific markets, customers and specific competitors, as well as various

(C) Tayebeh Nikraftar, Elahe Hosseini and Elham Mohammadi. Published in Revista de Gestão. Published by Emerald Publishing Limited. This article is published under the Creative Commons Attribution (CC BY 4.0) licence. Anyone may reproduce, distribute, translate and create derivative works of this article (for both commercial and non-commercial purposes), subject to full attribution to the original publication and authors. The full terms of this licence may be seen at http://creativecommons.org/licences/by/4.0/ legalcode 
skills (Nikraftar \& Hosseini, 2017). Entrepreneurship is also important in industries with high technological opportunities because it can lead to company success, engagement in entrepreneurship, and the simultaneous risk-taking of investment in product and technology development (Schaper, 2016). Technology transfer, commercialization and the development of a new product (the subject of technological entrepreneurship) can play an important role in creating a competitive advantage for various technology companies and organizations (Bridge \& O’Neill, 2012). In addition, technological entrepreneurship must be recognized as a multidimensional attribute (Linton \& Xu, 2021). Accordingly, Bailetti (2012) states that the field of technological entrepreneurship is comparable to different fields such as economics and management in childhood; the researcher then considered technological entrepreneurship as an investment in a project that is unique to individuals and collects and expands complexities related to scientific advances and knowledge management through its heterogeneous assets to create value in a company (Bailetti, 2012).

In addition, technological entrepreneurship is at the core of crucial negotiations and discussions around the foundation and growth of companies, the region's economic development, the selection of proper stakeholders for the ideas, and training of managers, engineers and scientists (Zhuo et al., 2018). The primary role of technological entrepreneurship is to integrate high-quality people and heterogeneous assets. In other words, it seeks to create and capture value for the company through shared experiences and discovery (Bailetti, 2012). Technological entrepreneurship refers to the innovative implementation of science and technical knowledge by an individual or a group of people while creating and managing a business and taking financial risks to achieve their goals and prospects (Etzkowitz \& Zhou, 2017).

Moreover, today we are witnessing rapid changes in technology and the intensity of the complexity of the environment (Salamzadeh, Tajpour \& Hosseini, 2019). Proper insight into the existing situation might enable managers to recognize market realities and related rules, it may also help them create new and valuable strategies (Saeeda Ardakani, Tajpour \& Hosseini, 2020).

Technology-based industries are expanding rapidly and are replacing traditional industries; hence, it is imperative to develop technological entrepreneurship (Groen, Cook \& Van der Sijde, 2015). These changes and knowledge-based activities are sometimes interpreted as the industrial revolution. According to the Organization for Economic Cooperation, it is clear that the development of technology plays a significant role in economic growth and development, while the emergence of technological entrepreneurship has led to the emergence of small and medium-sized enterprises (Dahlstrand, 2007). Manufacturing can revive, and technological management can be sought provided that national measures are integrated with this topic. Hence, it might be manifested in a framework that includes developed manufacturing leading to the establishment of policies pertinent to the particular conditions of each country (Daudt \& Willcox, 2018).

Since the early 2000s, the Iranian government has opted to encourage the shift toward a knowledge-oriented economy by implementing different procedures. For this purpose, they adopted the "Government's Vision 2025" established in 2005 and involved various policies regarding technology, revolution, and science (Naghizadeh, Allahy \& Ranga, 2020). Iran has also enacted new laws in 2010 supporting the foundation and improvement of SMEs as a mediator between business and science. These enterprises can help introduce the new products into the market and present the outcomes of the research and development (R\&D) departments in technological industries (Kanani \& Goodarzi, 2017).

While small and medium enterprises (SMEs) intend to improve the range of activities and the related market, their performance has been questioned by the competitive environment in developing countries (Hosseini, Saeida Ardekani \& Sabokro, 2020a). Besides, various factors such as the lack of interacting and technical skills, incorrect selection of technology,

Technological entrepreneurship 
REGE 29,1

insufficient obligation to learn novel technologies, as well as inadequate human capital have affected the consistency of such enterprises with the progression rate in the technological business in the world (Salisu \& Bakar, 2019). Three factors of "the number of studies," "the quality of studies" and "the number of nanotechnology inventions" can determine Iran's position in the area of nanotechnology. Accordingly, authors selected the Web of Science database as the statistical source, and the related studies would be searched, extracted, and measured based on appropriate keywords. Moreover, the number of nanotechnology inventions would be determined according to the reliable patent committees in the world, including United States Patent and Trademark Office (USPTO) and Europe Patent Office (EPO). Consequently, it was declared that Iran had registered 263 nanotechnology inventions in these two committees by the end of 2019 (Navabakhsh, Navabakhsh \& Shadnoosh, 2019). In addition, Iran has registered 16 Nano-patents in USPTO, and 24 Nano-inventions have been delivered to USPTO for further investigations throughout 2019. Accordingly, Iran ranked 24th among the registered patents in USPTO in 2019 (www.nano.ir).

Despite the growing tendency toward technological entrepreneurship and SMEs have attracted significant attention among the media and policymakers, there is still a little research-based knowledge available accordingly. Existing studies have focused on some concepts, ideas, and solutions; however, it is necessary to conduct further studies in this area, given that technological entrepreneurship is a relatively new topic of research (Najjari, Didehkhani, Mostaghimi \& Hosseini, 2021). It is believed that lack of consensus on the concept of technological entrepreneurship is regarded as the central issue because researchers commonly regard it as the combination of the concepts of entrepreneurship and technology where there is still no integrated definition for either of them (Babaei Fishani, Khozain, Ziyae \& Ashrafi, 2020). Furthermore, the field of technological entrepreneurship needs further investigation in Iran due to the lack of political stability and economic conditions, poor knowledge of managers and the lack of access to financial resources. Moreover, given that technological businesses and SMEs are highly dependent on human capital and exist in a competitive environment, it is necessary to conduct supplementary studies accordingly (Keikhakohan, Akbari \& Hejazi, 2020).

As a result, it is imperative to propose a model for the development of technological entrepreneurship in order to provide integrated plans and policies accordingly (Bolzani, Munari, Rasmussen \& Toschi, 2021). Previous studies indicate that executive managers have focused on the development and promotion of nanotechnology as an integral part of the technological foundation in Iran; besides, the development of nano-technological entrepreneurship requires a reliable and scientific model (Ghasemi, Navabakhsh \& Shadnoosh, 2019). The analysis of related scientific databases revealed that the identification of crucial factors in technological entrepreneurship had been disregarded in SMEs (Babaei Fishani et al., 2020). Consequently, the present research can contribute to filling the existing gap in this field given that data are collected from the corporates involved in the existing administrative plan supporting SMEs in Iran. The present research employs the Smart Specialization concept to encourage local improvement as a result of determining local potential and significant ventures that can help promote its competitive advantage. Consequently, it is likely to observe the establishment of the nanotechnology industry in developing areas that might result in entrepreneurship policies and prominent innovation in the region (Hosseininia, Yaghoubi Farani \& Afshar, 2014).

Hence, this study can help expand the literature in the field of technological entrepreneurship and make a relationship with the innovative nanotechnology industry. It will also indicate that technology, peripheral knowledge, resources and collaborations can lead to the enhancement of businesses. This study highlights the potential relationship between technological entrepreneurship and the concept of business. The authors can also claim that there is no similar study on the mediating role of contextual elements in this 
relationship. Thus, this study aims to identify the influential factors in the successful performance of technological entrepreneurship in small and medium enterprises among Iranian nanotechnology-based corporates.

\section{Literature review}

\section{Entrepreneurship and its types}

Entrepreneurship refers to the fundamental driving force in economic development through creating novelty and new combinations of materials (Nikraftar, Hosseini \& Moghadam, 2016). Entrepreneurship is largely focused on respective behaviors and decisions, exploration and exploitation of opportunities, as well as development and implementation of resources, which is necessary for the formation of a profitable business (Tajpour \& Hosseini, 2021a). Given that rebuilding strategies and innovation in organizations are based on identification and exploitation of opportunities requiring resources that are not necessarily available to entrepreneurs, all the components of entrepreneurship are significant (Bordbar, Monfared, Sabokro, Dehghani \& Hosseini, 2021). Therefore, entrepreneurship can be regarded as a set of strategic decisions and behaviors (Tajpour, 2021). In general, there are two types of entrepreneurships as follows: individual entrepreneurship, where the entrepreneur attempts to conduct entrepreneurship behaviors independently; corporate entrepreneurship, which can be defined as organizational entrepreneurship or entrepreneurship organization. The former refers to the process in which the entrepreneur explores and exploits new products, activities, procedures and technologies with the help of the organization. Consequently, entrepreneurship measures do not take place in isolation and are affected by institutional and governmental factors, business environment, as well as macro-economic conditions (Autio \& Rannikko, 2016). Therefore, productive entrepreneurship is the ultimate objective of entrepreneurship policies in different countries, which can lead to economic development. In addition, entrepreneurship is considered as a strategy for commercialization of novel ideas and new technologies (Entezari, 2015).

Previous studies in Iran concludes that technology refers to a strong source of competitive advantage that can modify optimal conditions in business affairs (Ziyae, Sadeghi, Nejad \& Tajpour, 2021). Technological features are reliant on science including constructive and multidimensional designs that are associated with values formed by society (Najjari, Didehkhani, Mostaghimi \& Hosseini, 2021). As a primary factor in creating individual and national wealth, the role of technological entrepreneurship has increased significantly during the past decades. Technological entrepreneurship measures can play a central role as technological innovations in developed economies and in the renovation of developing economies. Concerning the relationship between entrepreneurship and research-based technology, it can be noted that entrepreneurship can lead to innovation in new products, meeting social needs, creating jobs, as well as profitability of individuals and companies as a result of technological development (Najjari, Didehkhani, Mostaghimi \& Hosseini, 2021). Hence, technological entrepreneurship in SMEs can lead to innovative processes, increasing competitive advantage and sustainable activities in international business environment (Tajpour \& Hosseini, 2021b).

\section{Technological entrepreneurship: theories, elements and consequences}

Technological entrepreneurship involves the process of creating, exploiting and developing new technological opportunities in the marketplace (Machnik-Słomka \& Kordel, 2016). Technological entrepreneurship may define the possibilities of creating new products, introducing these products to the market and selling them at a price higher than production costs (Petti \& Zhang, 2011). Technological entrepreneurship refers to the potential in technological opportunities to successfully create successful businesses (Petti \& Zhang, 2011). 
REGE 29,1

Technological entrepreneurship is not just about discovering pre-existing options by conscious people and thinking about the future of their process (Tajpour, Hosseini \& Moghaddm, 2018). Instead, it involves creating new options by re-combining and transforming existing resources. These processes can be manifested in different ways depending on the initial conditions and future dynamics. Technology entrepreneurship can focus on humans' role in shaping new technologies (Garud \& Karnøe, 2003).

Technological entrepreneurship is a factor contributing to the success and prosperity of the individual, the company, the region and the nation (Bailetti, 2012). Technology entrepreneurship has many interactive dimensions. First, it is not just about discovery and thinking, it is about creation. Second, these actors affect the inputs, and third, these processes can vary depending on the type of technology path, and each provides a specific logic (Garud $\&$ Karnøe, 2003). Technological entrepreneurship is the innovative application of science and technology by an individual or group of people who create and manage a business and take financial risks to achieve their goals and prospects (Prodan, 2007). It can be argued that the technological entrepreneurship literature is on the way to development when the relationship between micro and macro factors between technological opportunities and entrepreneurial performance is examined. Petti and Zhang (2011) believed that the crucial role of technology in the growth of entrepreneurship in the first step was to work on the analysis of commercialization logic. Explaining the underlying mechanisms for understanding the nature of technological entrepreneurship is secondary. As a result, individuals and corporates intend to get involved in new businesses with the novel market based on a variety of strategies, including technological entrepreneurship (Soleimanpour, Hosseini \& Mirdamadi, 2013); it refers to the approaches used to explore and implement technologyoriented opportunities in the market. Hence, the central objective of these companies is to thrive in the new business rather than merely earning money (Keikhakohan, Akbari \& Hejazi, 2020). Also, what distinguishes technological entrepreneurship from other types of entrepreneurship such as social entrepreneurship, small business management and selfemployment are shared experiences and the production of new products, assets and their features that are complex to advance scientific and technical knowledge and property rights of the company's assets (Evers, Cunningham \& Hoholm, 2014).

\section{Technological entrepreneurship in emerging markets, with a focus on its challenges in these specific contexts}

It is believed that economic growth can be accelerated by small and medium enterprises, given that they are capable of creating wealth, increasing wages and creating job opportunities in different areas (Naghizadeh, Allahy \& Ranga, 2020). In addition, innovative enterprises are more likely to develop and can also have enhanced performance compared to other companies (Phan, Mian \& Lamine, 2016). Given that such companies can diminish the immigration of talents, help improve the economy and provide technical occupational opportunities, they can play a significant role in the local innovation system (Kanani \& Goodarzi, 2017). Moreover, SMEs are required to develop entrepreneurial foundations at the beginning stages that are regarded as a sustainable and competitive local system in the global market (Fernández-Serrano, Martínez-Román \& Romero, 2019). Accordingly, the government should propose appropriately integrated policies, either at the local level or within the country, to meet SMEs' demands and help establish new enterprises (European Commission, 2012). Since many enterprises, including SMEs, do not interact with state organizations and/or universities regularly, it is highly significant to pursue this objective in developing countries (Tajpour \& Hosseini, 2020).

Development and growth have always been the main focus of the policies and programs of different countries, and two critical ways to pursue it have been to provide optimal conditions for entrepreneurship as well as the development of technologies (Isenberg, 2011). Given that 
administrative enterprises can facilitate research and development in science and technology, it is likely to witness a shift within the legal context of novelty, science and technology; they can also reinforce the industry-university collaboration (Cota, Aguiar, de Souza Neto \& Benegas, 2020). Moreover, such relationships might be regarded as central while improving organizations, developing social and economic foundations and transferring knowledge and innovation (Ribeiro \& Nagano, 2018). The research and development (R\&D) department is not well-established in developing countries. Besides, governmental organizations, the public sector and research universities and associations mainly conduct related activities (Tajpour, Hosseini \& Salamzadeh, 2020a).

Nonetheless, there are infrequent interactions between research activities and teaching objectives, such as cooperation among industry, government and university (Liefner \& Schiller, 2008). Researchers are used to conducting studies and discuss their findings with other academicians; however, it is difficult to include the cooperative paradigm into the conventional role that is imagined for the scholars (Ribeiro \& Nagano, 2018). Although the pursuit of entrepreneurship and technology is important, the combination of the two is known as technological entrepreneurship and has the most significant impact on development, competitiveness, welfare, progress, and even justice in different societies (Siyanbola, Aderemi, Egbetokun \& Sanni, 2011). Undoubtedly, the emergence of technological entrepreneurship depends on the existence of favorable conditions and a suitable ground that is necessary to identify and explain it according to the specific national and regional characteristics (Nikraftar \& Hosseini, 2016).

Iran, with unique features such as substantial natural resources, young and educated human capital, and semi-governmental economic structure that seeks to achieve performance-oriented growth (Safari, 2018), in general, is faced with relative backwardness in the context of entrepreneurship and technology, and more specifically in the context of technological entrepreneurship as an essential way to achieve growth and development (Tajpour, Hosseini \& Alizadeh, 2021). Significant problems and weaknesses in this regard include severe weakness in government policies and operational plans, underdeveloped commercial and legal infrastructure, and insufficient funding, as well as a weakness in the innovation index (Monitor, 2016) and technology preparedness (Safari, 2018). In addition, such shortcomings have been noticed in field studies such as the report of the Iranian Entrepreneurship Association (2013). Compared to developed countries, these countries are more vulnerable due to various factors such as more investment risks, significantly lower capital entries, dependence on tourism and export, as well as fewer systematic markets. As a result, they may reasonably disregard SEMs, particularly startup businesses in some countries, including Iran (Salamzadeh \& Dana, 2020). Interestingly, small and medium enterprises are developed although Iran is experiencing severe sanctions and different limitations that are mainly influential in the entrepreneurship domain (Salamzadeh \& Kesim, 2017). Therefore, attention to knowledge-based enterprise in nanotechnology, which can be important in the development of the country, has been considered by researchers in this article.

\section{Technological entrepreneurship in nano biotechnology industry: a review of past studies}

Nanotechnology can produce new materials, tools, and systems by taking control at the molecular and atomic levels using properties that appear at those levels (www.nano.ir). For nanotechnology, applications in medical diagnosis, food, medicine, biotechnology, environment, energy, chemistry, physics, etc., have been considered, which makes this technology a transcendental and trans-sectoral field (Acharya \& Pal, 2020).

These technologies are central for adapting to local conditions, promoting the effective exploitation of resources, and helping improve standards of living considering the least negative influence on the environment (Iqbal, Tehseen, Anwar, Masooma \& Bashir, 2020). 
REGE

29,1

\section{2}

However, stimulus strategies that have been proposed by the government in developing countries are assumed unsatisfactory during the past three decades. Therefore, private sector is required to take part in nanotechnology commercialization efforts. However, the role of the government regarding the direction of technology dissemination has altered, and it is now adopting policies and procedures to improve the shift of technology to the private sector (Balachandra, Nathan \& Reddy, 2010).

Given that nanotechnology was recognized as a nationally significant technology in 2003, a particular committee was developed to pursue the enhancement of nanotechnology in Iran. They aimed to propose a framework for long-term activities in this field in Iran, and the government developed and declared a ten-year strategic plan for nanotechnology in August 2005. The "Future Strategic Plan" document would consider Iran among the top 15 countries in nanotechnology in the globe, and it would intend to promote this position to create wealth and improve the quality of life for the people (www.nano.ir).

Based on the implementation of the "Future Strategic Plan" document within two 3-year stages, the respective committee decided to make some modifications to improve the plans and proposed a complementary document to be implemented for another three years from 2010 to 2013 (www.nano.ir). The new document highlighted an integral tendency to commercialization and industrial development based on nanotechnology (Navabakhsh, Navabakhsh \& Shadnoosh, 2019). The basic eight plans in the complementary document included: encouraging and promoting the general knowledge about nanotechnology to enhance the stakeholders' participation in the development and exploitation of nanotechnology; developing and supporting necessary infrastructures for a comprehensive, timely, balanced and stable expansion of nanotechnology (Navabakhsh, Navabakhsh \& Shadnoosh, 2019); promoting international interactions and collaborations; developing and employing human resource capital regarding nanotechnology as well as promoting problem-oriented research; implementing purposeful nanotechnology studies to achieve central technologies; facilitating commercialization through necessary technological services for technologists and SMEs; improving industries using nanotechnology and expanding its market (Navabakhsh, Navabakhsh \& Shadnoosh, 2019); as well as making policies and evaluating objectives, strategies, policies, plans, and nanotechnology institutions. Furthermore, the committee decided to form an executive panel concerning each plan (Navabakhsh, Navabakhsh \& Shadnoosh, 2019).

It can also be said that the basis of technological entrepreneurship is reflected in a system whose actors are interacting in a series of activities related to technology identification and development, opportunity identification, product development and business creation (Phan, Mian \& Lamine, 2016). Environmental entrepreneurship capacities are inextricably linked and influenced by the environment in which they are developed. This environment consists of specific local conditions and a combination of relationship and institutional configurations that affect the development of technology and entrepreneurship (Evers, Cunningham \& Hoholm, 2014). Perhaps one of the salient features of this research is that researchers seek to conduct comprehensive research using both qualitative and quantitative approaches to identifying factors influencing the success of knowledge-based enterprise nanotechnology to make the results more reliable and generalizable to identify these key factors in organizations.

\section{Research methods}

It was an applied mixed method (qualitative-quantitative) study. Mixed methods research using a combination of open and closed data and qualitative and quantitative variables. Moreover, it was sequential mixed research. Qualitative and quantitative research is performed sequentially in this type of research, and finally, the results are expressed in 
combination. In this type of research plan, qualitative data are given more importance to gain a real insight regarding the issues and the nature of the topic (Cresswell, 1998). This may refer to some authentic experiences pertinent to the issues under examination that are particularly helpful while describing hidden and unanticipated subjects. It can also be influential for specific research (Palalic, 2017). Besides, we decided to apply this method because the core objective is to choose the individuals who are acquainted with such phenomena.

Consequently, it will be easier to comprehend the topic so that the samples can provide appropriate answers accordingly (Hosseini, Saeida Ardekani \& Sabokro, 2020a, b). It is also recommended because of the objective of the study and the internal judgment. Unlike quantitative studies, qualitative research is less likely to provide arranged procedures, particularly in terms of sampling (Palalic, 2017). In addition, in the data collection sequence, first qualitative data and then quantitative data are collected. Finally, based on the findings from qualitative data, the researcher tried to collect quantitative data to make generalizability possible. In this research, the literature was first reviewed. Then, the significant factors for the success of the enterprise in nanotechnology were identified. Moreover, the quantitative data were collected through questionnaires.

\section{Qualitative section}

In the qualitative part, to identify the success factors of nanotechnology businesses, the opinion of experts was collected through the interview method. The statistical population included university experts in nanotechnology and technological entrepreneurship and executives of knowledge enterprise, and theoretical saturation was used to confirm the number of samples. Thus, nine university experts were selected from Iranian public universities who were associate professors and above by snowball method. Besides, 8 managers of nanotechnology businesses with over five years of management experience provided that respective surveys and research projects have been conducted on technological entrepreneurship and nanotechnology. Moreover, semi-structured in-depth interviews were conducted to collect the data. A qualitative coding method was also implemented to analyze the data. The interview questions focused on entrepreneurial technology in nanotechnology businesses. The sequence of questions was not the same for all participants and depended on the interview process. There was not a pre-constructed pattern in the design of the interview questions. The researchers tried to conduct each interview focused on obtaining qualitative data independently and exploratory, regardless of past findings, and analyzing the results without any specific manipulation or mental model. The interviews were conducted in the form of individual meetings in presence, and the procedure continued until theoretical saturation was reached (see Figure 1).

In the present study, the questions were mainly formed with the following six wh-question marks: how, what, why, when, where and who (Hosseini, Saeida Ardekani, Sabokro \& Alhosseini Almodarresi, 2021). There were eight questions in this stage; for instance, "What are the effective indicators of technological entrepreneurship in nanotechnology businesses?", "What are the implications of technological entrepreneurship in nanotechnology businesses?", and "What are the factors that facilitate technological entrepreneurship in nanotechnology businesses?”. Each interview would be performed for 35-55 minutes on average; besides, axial and open coding approaches were used accordingly. Furthermore, the validity of research instruments was evaluated based on the following steps:

(1) Validation by participants: they were asked to review the secondary coding stage and provide their opinions accordingly;

(2) Peer review: respective professors were asked to examine the findings and express their views on the coding process; 


\section{REGE 29,1}

Figure 1.

Research processes

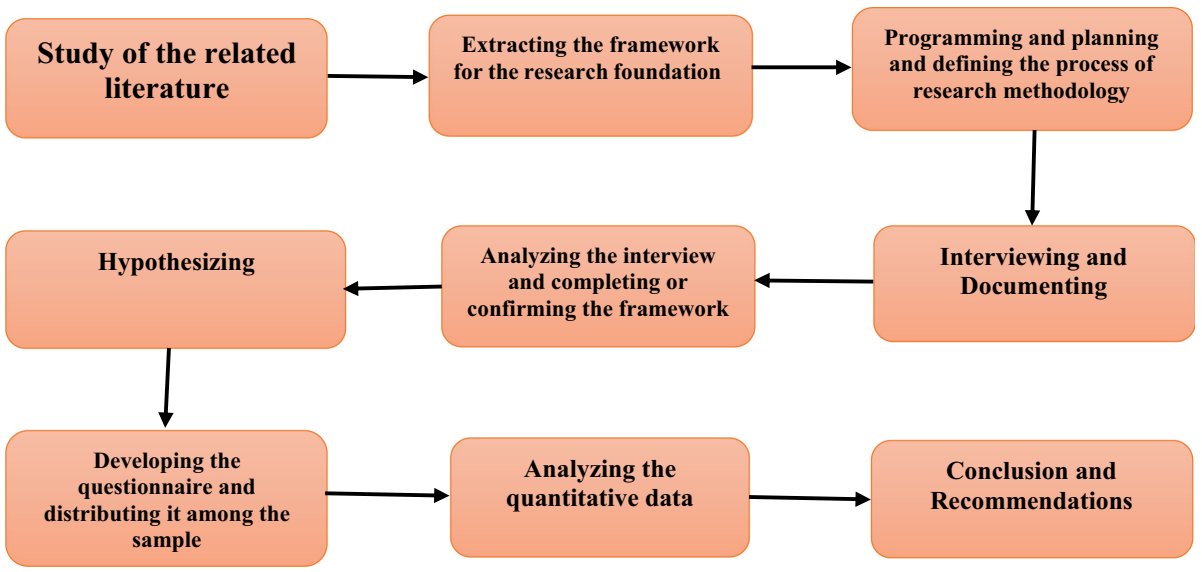

(3) Participatory research: research samples were invited to offer their opinions on the interpretation and analysis of the data; and

(4) Pluralism: it refers to the variety of participants (university experts and managers of nanotechnology), i.e. the samples belonged to different cultures and social levels.

Table 1 indicates that the inter-coders reliability coefficient was measured $74 \%$. In addition, the reliability of the present research was assessed based on the experts' opinions and evaluations using the following formulae:

$$
\text { C.R. }=\frac{(2 M)}{(N 1+N 2)}
$$

where $\mathrm{CR}$ refers to the reliability, $M$ refers to the number of codes based on consensus, and $N 1$ and $N 2$ refer to the first and second decisions.

The authors aimed to apply a process theory to provide efficient solutions for the problems regarding the grounded theory and explain the potential interactions over time. According to Strauss and Corbin, grounded theory approach requires researchers to continue the coding process until the selective coding stage. Hence, they are expected to develop

\begin{tabular}{lcccc}
\hline Components & $\begin{array}{c}\text { Reliability } \\
\text { coefficient }\end{array}$ & $\begin{array}{c}\text { Weight of each } \\
\text { component }\end{array}$ & $\begin{array}{c}\text { Reliability coefficient: } \\
\text { Weight of each } \\
\text { indicator }\end{array}$ & $\begin{array}{c}\text { Reliability } \\
\text { coefficient average }\end{array}$ \\
\hline $\begin{array}{l}\text { Technology } \\
\text { dimension }\end{array}$ & 0.75 & 0.93 & 0.70 & 0.74 \\
$\begin{array}{l}\text { Environmental } \\
\text { dimension }\end{array}$ & 0.91 & 0.80 & 0.73 & \\
$\begin{array}{l}\text { Individual dimension } \\
\begin{array}{l}\text { Organizational } \\
\text { dimension }\end{array}\end{array}$ & 0.86 & 0.72 & 0.62 & \\
$\begin{array}{l}\text { Technological } \\
\text { entrepreneurship }\end{array}$ & 0.83 & 0.94 & 0.78 \\
$\begin{array}{l}\text { Institutional } \\
\text { dimension }\end{array}$ & 0.78 & 0.87 & 0.68 & \\
\hline
\end{tabular}

Table 1.

Reliability coefficient 
a theory throughout the data collection stages (Hosseini, Saeida Ardekani \& Sabokro, 2020a, b).

\section{The clarification of model development process for technological entrepreneurship}

Three approaches of design, adaptation and adaptation-design are commonly applied to develop technological entrepreneurship patterns. Nonetheless, the present study used the design approach. As a result, respective model development and model assessment processes among Iranian nanotechnology enterprises were performed based on the following stages:

(1) Preliminary planning

This stage includes the determination of values and paradigms, philosophical grounds, strategies and objectives for technological entrepreneurship, components and the implementation of the model, and approaches. It also contains participants, extraction criteria and procedures.

(2) Preparing a preliminary list of technological entrepreneurship using individual interviews:

This stage refers to the implementation of interviews to determine underlying factors in technological entrepreneurship. Then, these components will be extracted based on the analysis of experts' opinions, and the initial list will be developed accordingly. Theoretical saturation was reached after performing 17 interviews in this study, and the demographic characteristics of participants such as age, education and gender, are provided in Table 2.

(3) Comparing the obtained list with the lists and the pattern of technological entrepreneurship

Open and selected coding processes were used for the analysis of qualitative data. It is also noteworthy that these two steps are interconnected and may occur together (Tajpour, Kawamorita, \& Demiryurek, 2020b). At first, appropriate titles were assigned to primary themes, and respective categories were developed accordingly. Eventually, the principal

\begin{tabular}{lllll}
\hline Interviewees code & Age & Gender & Degree & Major \\
\hline P1 & 52 & Male & PhD & Entrepreneurship \\
P2 & 38 & Male & PhD & Polymer Engineering \\
P3 & 43 & Male & MA & Medical \\
P4 & 34 & Female & PhD & Physics \\
P5 & 61 & Female & PhD & Materials Engineering \\
P6 & 58 & Male & MA & Medical \\
P7 & 63 & Male & MA & Chemical Engineering \\
P8 & 47 & Male & PhD & Environment \\
P9 & 52 & Male & PhD & Agricultural Engineering \\
P10 & 47 & Male & MA & Management \\
P11 & 39 & Male & PhD & Engineering \\
P12 & 41 & Male & PhD & Entrepreneurship \\
P13 & Female & MA & Management \\
P14 & 46 & Female & MA & Electrical Engineering \\
P15 & 50 & Female & PhD & Entrepreneurship \\
P16 & 37 & Female & MA & Management \\
P17 & 45 & Female & PhD & Materials Engineering
\end{tabular}

Table 2. Demographic characteristics 
REGE

29,1

\section{6}

category was extracted based on the relationships between the primary categories, which could lead to the development of a theory to illuminate the issue.

Irrespective of the potential relationships, several codes will be extracted in the open coding stage (Cresswell, 1998). A line-by-line approach was used to conduct open coding where the data were collected inside the study setting and analyzed externally. It is also noteworthy that the data will be assessed meticulously in this approach. At this stage, the ultimate code was extracted due to integrating open codes with the researcher's notes. In the next step, i.e. axial coding, the codes were integrated based on categorization. Then, relationships between the codes were explained using selective coding (Denzin \& Lincoln, 2005).

Ultimately, the researchers would compare primary codes with the outcomes of previous studies in order to extract new components. These components were then added to the original list of technological entrepreneurship. The final list (No. 2) of the extracted codes was formed after reviewing the content and analyzing the sources.

(4) Providing a definition for technological entrepreneurship concepts:

This step includes researchers' evaluation of the technological entrepreneurship assigned to lists No. 1 and 2. After integrating the results of the interviews with other resources, the final draft for the entrepreneurship index was formed. The categorization of extracted codes was performed using conceptual correspondence, respectively (see Table 3).

(5) Evaluating and refining the list of technological entrepreneurship

The narrative approach was implemented to collect the data from the individual interviews. For this purpose, the Delphi method was applied for model development as follows: At first, a Delphi panel was developed, and samples were identified after providing a comprehensive explanation of the objectives and problem of the present research. Selected experts would then receive an invitation along with the central components and practical factors in order to comment on the need to add to or reduce the proposed components. The second stage included the development of a questionnaire for technological entrepreneurship components; this instrument was designed according to the results of previous studies in the literature as well as in-depth exploratory interviews. The questionnaire was sent to the panel of experts to receive their constructive feedback. Eventually, the ultimate model of technological entrepreneurship for Iranian nanotechnology enterprises was developed when the experts

Table 3.

Behavioral evidence from the interviews for the initial coding

Behavioral evidence
Organizational strategies should be developed according to the
customers' needs after consulting the members. The objectives and
strategies of each field should be determined and defined. Providing a
proper definition of the objectives at early stages may help achieve the
goals in the future. Thus, there is a need for appropriate strategies in
order to adapt technology to the market
Proper and timely implementation of activities and processes (e.g.
research and development, developing and modifying strategies,
marketing, as well as developing human and financial resources) are
highly significant among SMEs
We allocate considerable money for the implementation phase, but not
for research in Iran. Nonetheless, research can be regarded as the
executive guarantee for the projects. Therefore, the appropriate
classification, planning and implementation of central and
complementary processes may lead to organizational success

Extracted codes

Developing strategies based on the customers' needs Developing strategies consistent with technology

Performing duties accurately Enhancing human resources Highlighting research and development 
assessed the items. The interviews were stopped after obtaining data saturation and the data were categorized into different groups. The final model contained 43 selected codes as well as 127 open codes (see Table 4).

\section{Quantitative section}

Eleven nanotechnology-oriented companies, including manufacturers of nanotechnology products, manufacturers of nanotechnology equipment, product development companies, patent service companies, policymaking institutions, nanotechnology research centers, nanotechnology laboratories, as well as market development companies, were taken into account by the authors in the quantitative phase. In the end, 96 companies with high research ranks were identified by the president scientific department, and the statistical population included all the 96 managers of the selected companies.

In the quantitative analysis, using the interview results and its coding and after the validity test, a questionnaire was prepared and sent to 75 experts and managers of the Special Staff for the Development of Nanotechnology and Knowledge Enterprise Nanotechnology. The required sample size was estimated 75 according to Cochran's formulae. Consequently, 75 questionnaires were distributed among available managers and experts in SMEs. All the questionnaires were completed and analyzed accordingly.

Based on the analysis of the quantitative phase, $62 \%$ of the respondents were male and $37 \%$ were female; besides, $93 \%$ hold a Ph.D. degree and $6 \%$ hold a Master's degree. Moreover, $12 \%$ of the participants were single and $87 \%$ were married. Finally, $25 \%$ of the respondents had 5 years of experience, $50 \%$ had between 5 and 10 years of experience, and $25 \%$ had over 10 years of experience.

The questionnaire was completed by 75 participants and the data were analyzed using PLS3 software. Since the normal distribution is not mandatory, the authors employed this software where the sample size was lower than two hundred (Tajpour, Hosseini \& Alizadeh, 2021). Partial least square method was employed to assess the reliability of the questionnaire. For this purpose, confidence and composite reliability were measured. Studies showed that the Cronbach's alpha coefficient and the composite reliability were more significant than the acceptable value of 0.7 for the entire constructs. Moreover, the obtained average extracted variance (AVE) and common reliability was reported higher than the minimum acceptable values of 0.5 for all the constructs. Therefore, the constructs of the present study converge in the desired way (Nikraftar \& Hosseini, 2017). According to Table 5, because all indicators had an AVE above 0.5 , convergent validity was established in all indicators.

The average variance index was used to measure the divergent validity. Accordingly, the AVE should be greater than the variance between that construct or variable and other constructs or variables (Hosseini, Tajpour, \& Lashkarbooluki, 2020c). In other words, the square root of the mean of the absolute extracted variance of the correlation between that variable and the other variables of that model was larger.

Based on the results of SmartPLS3 software in Tables 5 and 6, the validity (convergent and divergent) and reliability (combined reliability coefficient and Cronbach's alpha) of the measurement model were appropriate. Different criteria were applied to assess the fitness of the structural model through the least partial square method, which is the first and most essential criterion of significant coefficients or $T$-statistical values (Tajpour, Hosseini, \& Salamzadeh, 2020a). The fitness of the structural model using $T$-coefficient values should be higher than 1.96 to indicate acceptable fitness for the structural model at $95 \%$ confidence level. Figure 2 indicates the validity and significance of all paths between the variables of the model.

The $R^{2}$ coefficient was also used to examine the appropriateness of the structural model and refers to the latent endogenous variables. The $R^{2}$ can help evaluate the effect of 


\section{REGE}

29,1

\section{8}


exogenous variables on an endogenous variable where the values of $0.19,0.33$ and 0.67 are regarded as weak, moderate, and $R^{2}$ solid values (Fornell \& Larcker, 1981).

These criteria are depicted in the structural model of the research; since there was a latent endogenous variable in the present model, the value of zero was regarded for the other five circles. Figure 3 reveals that the $R^{2}$ criterion was greater than 0.33 (indicating strong values); thus, the structural model was appropriate from the perspective of this criterion.
Technological entrepreneurship

\begin{tabular}{lcccccr}
\hline & AVE & Rho-A & CR & Cronbach's alpha & $R^{2}$ \\
\hline Technology & 0.839 & 0.940 & 0.927 & 0.904 & - & \\
Environment & 0.666 & 0.888 & 0.720 & 0.867 & - & \\
Individual & 0.811 & 0.928 & 0.915 & 0.886 & - & Table 5. \\
Organizational & 0.703 & 0.716 & 0.958 & 0.712 & - & AVE, combined \\
Technological entrepreneurship & 0.600 & 0.856 & 0.795 & 0.777 & 0.574 & $\begin{array}{r}\text { reliability, and } \\
\text { Cronbach's alpha } \\
\text { Institutional }\end{array}$ \\
\hline
\end{tabular}

\begin{tabular}{|c|c|c|c|c|c|c|c|}
\hline & 1 & 2 & 3 & 4 & 5 & 6 & \\
\hline Technology & 0.916 & & & & & & \\
\hline Environment & 0.723 & 0.816 & & & & & \\
\hline Individual & 0.773 & 0.786 & 0.901 & & & & \\
\hline Organizational & 0.506 & 0.476 & 0.523 & 0.687 & & & Table 6. \\
\hline Technological entrepreneurship & 0.229 & 0.366 & 0.226 & 0.635 & 0.775 & & Divergent validity of \\
\hline Institutional & 0.829 & 0.803 & 0.808 & 0.561 & 0.265 & 0.885 & latent variables \\
\hline
\end{tabular}

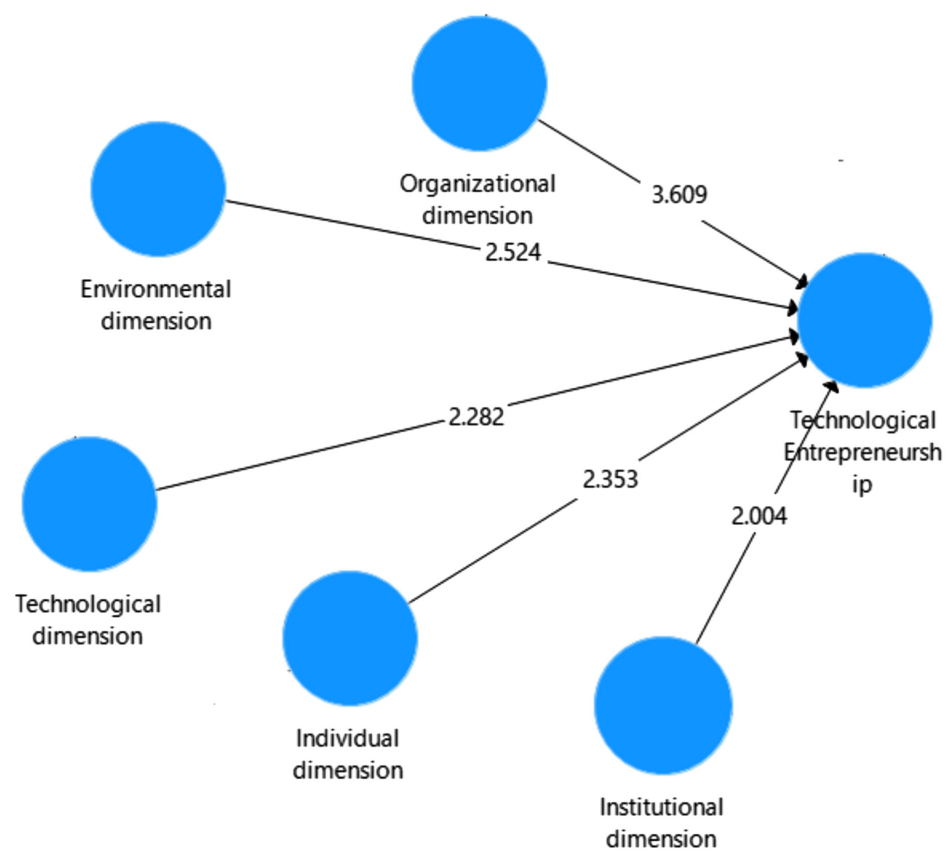

Figure 2. $T$-statistics 
REGE
29,1

90

Figure 3.

Model in standard coefficient load factor

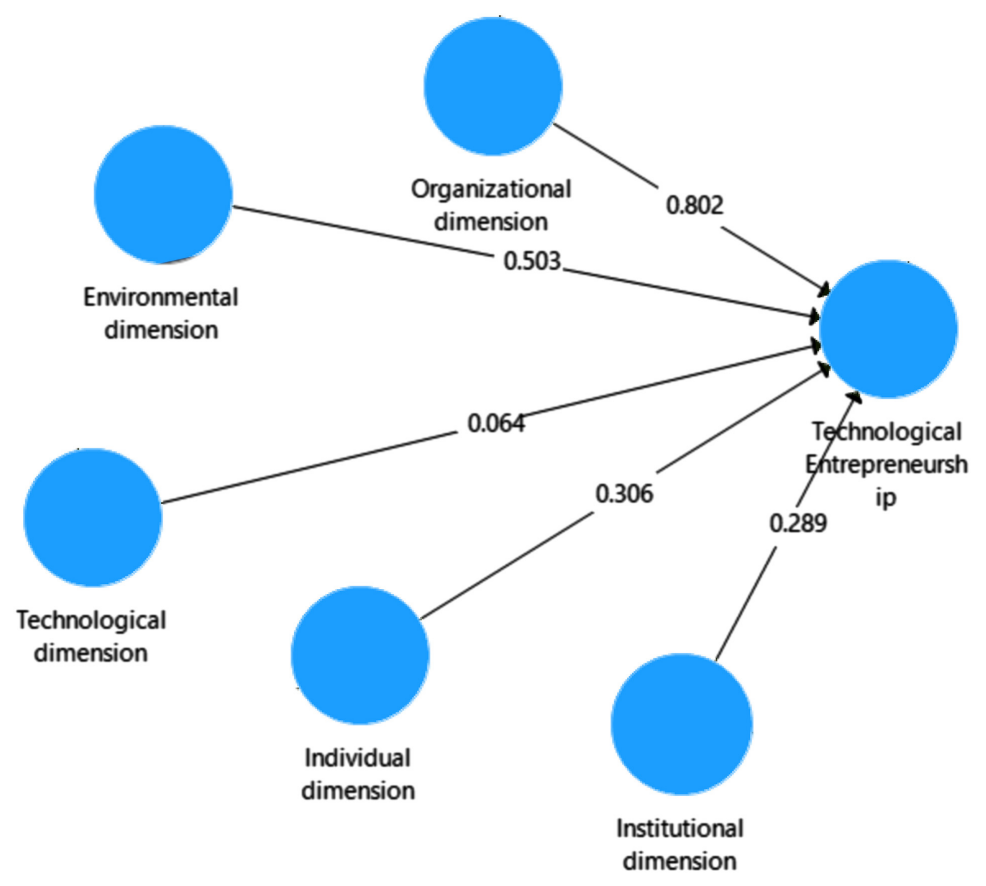

Goodness of fit (GOF)

The general model includes both measurement and structural model sections, and by confirming its fitness, the fitness is examined in the complete model. Consequently, the overall fitness of the model is conceivable according to GOF fitness (Fornell \& Larcker, 1981). The overall fitness of the model was very appropriate and approved since the obtained value of GOF was 0.708 . Besides, the three values of $0.01,0.25$, and 0.36 were regarded as the weak, medium, and strong values for GOF (Fornell \& Larcker, 1981). Therefore, the obtained value of 0.708 indicates a strong fitness of the overall research model. Based on the results, the fitness of the recommended model was confirmed in two parts, measurement and structure.

\section{Testing hypotheses}

$T$-statistics were employed to investigate the expected relationships between the variables. Five sub-hypotheses have been used to measure the main hypothesis, and as Table 7 shows, the $T$-factor for the five existing relationships has been confirmed that is an affirmation for the central hypothesis. Standardized factor load was used to determine the effect of predictive

\begin{tabular}{llccl}
\hline No & Path & $t$-statistics & Effect size & Hypothesis test \\
\hline 1 & Technological entrepreneurship - Organizational & 3.609 & 0.802 & Confirmed \\
2 & Technological entrepreneurship - Environmental & 2.524 & 0.503 & Confirmed \\
3 & Technological entrepreneurship - Institutional & 2.004 & 0.289 & Confirmed \\
4 & Technological entrepreneurship - Technological & 2.282 & 0.064 & Confirmed \\
5 & Technological entrepreneurship - Individual & 2.353 & 0.306 & Confirmed \\
\hline
\end{tabular}

Table 7.
T-Statistics and effect size coefficients 
variables on dependent variables regarding the pathways of each hypothesis. The obtained coefficients indicated that changes in dependent variables can be partly explained by independent variables.

The results showed that the $T$-statistic for all paths was higher than 1.96 , which indicated the confirmation of the hypotheses; therefore, with $95 \%$ confidence, it can be said that the factors affecting technological entrepreneurship had a positive and significant effect.

\section{Discussion}

The primary purpose of the research was to identify the key factors influencing the success of technological entrepreneurship in nanotechnology. The key factors affecting the success of the technological entrepreneurship process in knowledge enterprise in the field of nanotechnology were identified and the data were classified into five general categories, including organizational, environmental, institutional, individual and technological dimensions. The finding of the present study was incongruent with the study done by Keikhakohan, Akbari and Hejazi (2020), Kanani and Goodarzi (2017). However, the findings contradict the results of Naghizadeh, Allahy and Ranga (2020) study. They found that economic and commercial components have crucial roles in technological entrepreneurship.

Moreover, the results revealed that environmental and organizational factors have the most significant impact on technological entrepreneurship. The environment includes both the industry in which the business operates and the macro environment, including government and its policies. Based on, the environment in which a business operates affects the success of its idea. The impact of the environment on business is such that the manager wants to respond it creatively.

Other factors influencing technology entrepreneurship are organizational factors such as organizational strategy and management. Studies show that organizational factors such as organizational structure, strategy and managerial support are essential to boosting entrepreneurship in business. The present study fills the scientific gap (Maine, 2014), what influences uncertainty between idea discovery and production in knowledge-based businesses (Covin \& Slevin, 1991). Therefore, the results pointed that taking advantage of internal capabilities such as workforce and financial power will help nanotechnology SMEs in Iran succeed. Using targeted training to train professionals who can provide expertise in this area can be effective. The organization must take steps to achieve its goals by strengthening collaboration between employees and creating the proper organizational structure that responds to rapid and sudden changes.

The individual components refer to characteristics and capabilities of the staff. According to Shane and Venkataraman (2000) as well as Ghasemi, Navabakhsh and Shadnoosh (2019), these components may include high risk-taking, ambiguity tolerance, self-confidence, resilience and feeling implacable. Besides, it can be said that enterprises should improve their staffs' abilities and skills. Accordingly, Salamzadeh, Tajpour and Hosseini (2020) asserted that individuals should attempt to promote their skills and capabilities through acquiring knowledge and experience and to collect, transfer, and select the necessary information and resources through academic and non-academic courses. They are also suggested to improve their social relationships in order to identify opportunities that may arise from environmental changes. This will help nanotechnology enterprises in Iran gain pertinent experience and resist negative effects of environmental threats.

In addition, unemployment that is one of the most critical problems of the country will be partially solved by creating institutions that teach technological entrepreneurship skills. Moreover, by increasing the motivation of individuals and forming group networks to start a business in this field, an effective step can be taken in the success of these businesses. 
REGE

29,1

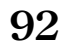

Yan, Li and Zhang (2021) believed that, given that SMEs include innovative and flexible networks that facilitate marketing and investment, they can lead to future success in the ground-breaking environment. Moreover, Salamzadeh, Tajpour and Hosseini (2020) believed that enterprises should take into account the customers' demands such as establishing a personal approach and building intelligent, innovative, and reciprocal relationships which include sympathy. Therefore, SMEs in the field of nanotechnology in Iran are also more likely to attract investment and facilities authorize related projects, and obtain competitive advantage as a result of establishing such networks, appropriate perception of technological entrepreneurship, development of necessary grounds for investment, development of intraorganizational relationships, providing consultations and adaption of market demands with the novel technologies in the region.

Regarding the institutional component, it can be stated that policymakers must pass policies in supporting that technological entrepreneurship in SMEs in the field of nanotechnology. The government must support domestic production, amend tax laws, insurance laws and enact protectionist laws, optimize technology policies, financial policies, market policies and increase policies related to international interactions and the level of culture in nanotechnology to develop technological entrepreneurship in these companies. The government's policies should be based on increasing the technology absorption coefficient, increasing market demand for products in this area, and developing market policies in nanotechnology. Furthermore, Bahrami, Azizi, Badizadeh and Rezghi Shirsavar (2019) claimed that systematic implementation of research and development programs can lead to greater institutional success. Workforce should be trained by universities, and policies should be based on increasing the professional force needed to create a competitive advantage. As society's awareness grows, we should increase the size of the market in terms of product and service development. Shane and Venkataraman (2000) as well as Reynolds, Camp, Bygrave, Autio and Hay (2002) highlighted the government's role in supplying infrastructures, offering financial support, and providing necessary information and instructions. Therefore, governments should attempt to develop capital through risky investors to improve the capital, organizations and companies' condition. Kim, Yang, Lessmann, Ma, Sung and Johnson (2020) declared that the crucial policy should be to facilitate the provision of loans to technology producers and increase the number of foreign investment and help the Nano investment fund in any way possible. Accordingly, it is noteworthy that the government has taken the following steps to help enhance nanotechnology enterprises in Iran: revising the laws in order to provide legal and facilitating grounds for these enterprises, developing proper inter-organizational relationships to gain scientific and technological empowerment, and reducing or removing bureaucracy.

The enhancement of risky investment requires institutional modifications and policymakers can play a crucial role in this regard. Hence, it is recommended that policymakers should attempt to reform the institutions through motivating respective improvement and creating interactions between the investors and entrepreneurs rather than having a direct effect on the establishment of financial organizations/institutions or funding nanotechnology SMEs.

Lundström and Stevenson (2002) asserted that meeting the financial need of nanotechnology enterprises through the "Equal Rights of Business Owners" plan is regarded risky; however, unregistered enterprises will receive short-term or pay-back guaranteed loans. Such support and attention to financial issues of nanotechnology SMEs in Iran might lead to the quick development of these companies. The government also is required to pass bills on the Intellectual Property Registration Organization. The Intellectual Property Rights Protection Organization and the Patent Office play a key role in registering and protecting intellectual property rights today. Nazarian, Lee, Siegel, Kuo, Acharya and Schmidt (2021) argued that the government should oversee the work of institutions that issue 
standard licenses and scientific and technological licenses to operate in the field of nanotechnology to allow the production of products that are eligible for health, safety and are non-harmful to humans and the environment. In this regard, Motiei, Moradi, Arabiun and Meigounpoory (2019) concluded that governments' policymaking can influence strategic procedures and indicate the orientation of entrepreneurship activities. Proper strategic procedures might ensure the success of Iranian nanotechnology SMEs in the competitive international and, particularly, middle eastern environment. Moreover, Weiss (2020) stated that central objectives of the government should include determining, compiling and publishing national standards, conducting research to develop standards, improving the quality of domestic goods, helping improve production methods, increasing the efficiency of industries for the self-sufficiency of the country and promoting standards, promoting national standards on monitoring the implementation of compulsory standards, quality control of exported goods subject to mandatory standards and prevention of the export of substandard goods in order to provide competition with similar foreign goods and maintaining international markets, quality control of compulsory import goods to protect consumers and domestic producers. Creating the proper infrastructure to shape and strengthen activity in this area can help these businesses succeed.

Therefore, it is imperative for nanotechnology SMEs to design their structural, infrastructural and scientific measures to meet the needs of the society. It is also recommended to create industrial clusters to provide faster services and reduce the costs of businesses in these clusters.

Technological entrepreneurship has been regarded as an integral source of creating economic value and development. It aims to build a connection between technological development and the creation of businesses. Therefore, Weiss (2020) believe that transferring technology is considered a crucial process that requires accurate and comprehensive exploitation in order to avoid wasting capital and time as well as diminishing technology. It may also lead to delayed and costly achievement of ultimate product. This is a reciprocal process and both sides of the relationship should accomplish their aims and benefits while confirming values of each party. Hence, stakeholders of science and technology sector are ultimately required to make money through knowledge. Universities may not be able to accomplish this objective and it is necessary to create and support technological and knowledge-based infrastructures as well as highlight the dynamic nature of universities to benefit from the knowledge and develop a knowledge-oriented economy. Advancement in knowledge can result in the creation of technology and making money; however, it is crucial to propose appropriate plans and policies and create necessary infrastructures in order to achieve this objective.

\section{Theoretical, practical (business managers) and policy implications}

Entrepreneurship is regarded as the forcing power of economic and social development in societies that plays a crucial role in the development of nanotechnology applications and exploitation of its numerous benefits. In other words, strategic entrepreneurship can benefit from the capacities and capabilities of new technologies to achieve sustainable development. Technological entrepreneurship can indicate the collaboration between strategic entrepreneurship and developmental capacities of new technologies. Given the unique characteristics of nanotechnology such as high growth rate, the close relationship between research and market, multidisciplinary nature and the need for group activities, the transitory nature of technology, risky investment, as well as the wide range of impact on various fields, it is imperative to identify effective factors in technological entrepreneurship among SMEs. Consequently, specialists believe that nanotechnology should be considered a priority for all countries because of its wide range of practicality and effectiveness in the 
REGE

29,1

94

majority of industries. They have also asserted that nanotechnology will significantly influence global markets in the near future. In other words, nanotechnology is recognized as entrepreneurship-oriented technology with the ability to propose new economic opportunities that can lead to the creation of novel businesses as well as the provision of more services and products in the existing competitive environment. As a result, the development of technological entrepreneurship is considered a major step toward sustainable enhancement of nanotechnology given the unique nature of nanotechnology regarding numerous innovations in different economic areas. Nonetheless, it might be impossible to benefit from various capabilities of nanotechnology without implementing a specific strategy. Finally, it can lead to transferring technology, commercialization, and product development through the identification and exploitation of business opportunities in a dynamic environment.

\section{Limitations and future research}

Although the present study had significant contributions, there were some shortcomings as well. Regarding the study population, a few nanotechnology business managers were reluctant to take part in this survey because of their partial responses or their conservative nature. Furthermore, it was impossible to include all the affective factors and different characteristics of technological entrepreneurship due to various cultures. These limitations may affect the generalizability of the study outcomes. Consequently, the authors would recommend other academicians to implement the same model in order to perform parallel studies in different cultures or different companies. They can also make a comparison between the conclusions of their research and the results of the present study that leads to the advancement of the generalizability of the outcomes.

In addition, it is suggested to conduct further comprehensive studies on nanotechnology subjects because of the significant effects of various factors on the accomplishment of technological entrepreneurship process, particularly in small and medium enterprises. The improvement of the performance of these factors may also lead to the evolution of SMEs involved in the nanotechnology perspective.

\section{References}

Autio, E., \& Rannikko, H. (2016). Retaining winners: can policy boost high-growth entrepreneurship?. Research Policy, 45(1), 42-55. doi: 10.1016/j.respol.2015.06.002.

Acharya, A., \& Pal, P.K. (2020). Agriculture nanotechnology: Translating research outcome to field applications by influencing environmental sustainability. Nano Impact, 100232. doi: 10.1016/j. impact.2020.100232.

Babaei Fishani, M., Khozain, A., Ziyae, B., \& Ashrafi, M. (2020). Designing a model of technological entrepreneurship financing ecosystem in knowledge-based business case study: Information technology and communication. Accounting and Auditing Research, 12(48), 177-192.

Bahrami, H., Azizi, M., Badizadeh, A., \& Rezghi Shirsavar, H. (2019). Institutional factors affecting the internationalization of pharmaceutical technology companies. Journal of Healthcare Management, 10(1), 19-30.

Bailetti, T. (2012). Technology entrepreneurship: Overview, definition, and distinctive aspects. Technology Innovation Management Review, 2(2), 3-12.

Balachandra, P., Nathan, H.S.K., \& Reddy, B.S. (2010). Commercialization of sustainable energy technologies. Renewable Energy, 35(8), 1842-1851. doi: 10.1016/j.renene.2009.12.020.

Bolzani, D., Munari, F., Rasmussen, E., \& Toschi, L. (2021). Technology transfer offices as providers of science and technology entrepreneurship education. The Journal of Technology Transfer, 46(2), 335-365. doi: 10.1007/s10961-020-09788-4. 
Bordbar, G., Monfared, A.K., Sabokro, M., Dehghani, N., \& Hosseini, E. (2021). Human resources competencies scale development and validation: An Iranian measure. Industrial and Commercial Training, 53(3), 250-267. doi: 10.1108/ICT-03-2020-0028.

Bridge, S., \& O'Neill, K. (2012). Understanding enterprise: Entrepreneurship and small business: Macmillan International Higher Education, Palgrave Macmillan.

Chitsaz, E., Tajpour, M., Hosseini, E., Khorram, H., \& Zorrieh, S. (2019). The effect of human and social capital on entrepreneurial activities: A case study of Iran and implications. Entrepreneurship and Sustainability Issues, 6(3), 1193-1203. doi: 10.9770/jesi.2019.6.3(24).

Cota, V.R., Aguiar, C.L., de Souza Neto, B., \& Benegas, M. (2020). Open-source hardware as a model of technological innovation and academic entrepreneurship. Innovation \& Management Review, 17(2), 177-195. doi: 10.1108/INMR-06-2018-0036.

Covin, J.G., \& Slevin, D.P. (1991). A conceptual model of entrepreneurship as firm behavior. Entrepreneurship Theory and Practice, 16(1), 7-26.

Cresswell, J.W. (1998). Qualitative Inquiry and Research Design: Choosing Among Five Traditions, Washington, DC: Sage Publications.

Dahlstrand, Å.L. (2007). Technology-based entrepreneurship and regional development: the case of Sweden. European Business Review, 19(5), 373-386. doi: 10.1177/104225879101600102.

Daudt, G., \& Willcox, L.D. (2018). Critical thoughts on advanced manufacturing: the experiences of Germany and USA. Revista de Gestão, 25(2),178-193. doi: 10.1108/REGE-12-2017-0016.

Denzin, N.K., \& Lincoln, Y.S. (2005). Introduction: The Discipline and Practice of Qualitative Research, Washington, DC: Sage Publications.

Entezari, Y. (2015). Building knowledge-based entrepreneurship ecosystems: Case of Iran. ProcediaSocial and Behavioral Sciences, 195, 1206-1215. doi: 10.1016/j.sbspro.2015.06.242.

Etzkowitz, H., \& Zhou, C. (2017). The Triple Helix: University-Industry-Government Innovation and Entrepreneurship. London: Taylor \& Francis Group.

European Commission (EC) (2012). Guide to Research and Innovation Strategies for Smart Specialisations (RIS3). Publications Office of the European Union. Luxembourg: European Union.

Evers, N., Cunningham, J., \& Hoholm, T. (2014). Technology Entrepreneurship: Bringing Innovation to the Marketplace. Springer.

Fernández-Serrano, J., Martínez-Román, J.A., \& Romero, I. (2019). The entrepreneur in the regional innovation system. A comparative study for high-and low-income regions. Entrepreneurship and Regional Development, 31(5-6), 337-356. doi: 10.1080/08985626.2018.1513079.

Fornell, C., \& Larcker, D.F. (1981). Evaluating structural equation models with unobservable variables and measurement error. Journal of Marketing Research, 18(1), 39-50. doi: 10.1177/ 002224378101800104.

Garud, R., \& Karnøe, P. (2003). Bricolage versus breakthrough: Distributed and embedded agency in technology entrepreneurship. Research Policy, 32(2), 277-300. doi: 10.1016/S0048-7333(02) 00100-2.

Ghasemi, E., Navabakhsh, M., \& Shadnoosh, N. (2019). Discovering technology entrepreneurship opportunities in nanotechnology. Journal of Iranian Social Development Studies, 11(44), 21-42.

Groen, A., Cook, G., \& Van der Sijde, P. (2015). New Technology-Based Firms in the New Millennium. Emerald Group Publishing.

Hosseini, E., Saeida Ardekani, S., \& Sabokro, M. (2020a). Conceptual model of the voice of the members of the scientific board of public universities of Iran with the approach of interpretive structural modeling. Journal of Research on Management of Teaching in Marine Sciences, 7(4),16-41.

Hosseini, E., Saeida Ardekani, S., \& Sabokro, M. (2020b). Presentation the pattern of knowledge employees voice (case study: Shiraz gas company employees). Quarterly Journal of Public Organzations Management, 8(4), 57-72. doi: 10.30473/IPOM.2020.51818.4039. 
REGE 29,1

Hosseini, E., Tajpour, M., \& Lashkarbooluki, M. (2020c). The impact of entrepreneurial skills on manager's job performance. International Journal of Human Capital in Urban Management, 5(4), 361-372. doi: 10.22034/IJHCUM.2020.04.08.

Hosseini, E., Saeida Ardekani, S., Sabokro, M., \& Alhosseini Almodarresi, S.M. (2021). Developing a model for knowledge employee voice (case study: Information technology small and medium enterprises). Organizational Culture Management. a head of print. doi: 10.22059/jomc.2021. 305993.1008085.

Hosseininia, G., Yaghoubi Farani, A., \& Afshar, S. (2014). Environmental factors affecting technological entrepreneurship in Electric Industry. Iranian Electric Industry Journal of Quality and Productivity, 3(1), 8-17.

Iqbal, T., Tehseen, A., Anwar, M., Masooma, S., \& Bashir, A. (2020). A short review on role of nanotechnology in daily life. Research and Reviews: Journal of Computational Biology, 8(3), 24-33.

Isenberg, D. (2011). The entrepreneurship ecosystem strategy as a new paradigm for economic policy: Principles for cultivating entrepreneurship. Presentation at the Institute of International and European Affairs, 1, 13.

Kanani, M., \& Goodarzi, M. (2017). Fostering new technology-based firms in Iran: Inspiration of world models in solving domestic challenges. The Development of Science and Technology in Iran. Palgrave Macmillan, New York, pp. 29-43. doi: 10.1057/978-1-137-57257-8_3.

Keikhakohan, J., Akbari, M., \& Hejazi, S.R. (2020). Identifying barriers to development of regional technological entrepreneurship (case study: Sarbaz county). Journal of Rural Research, 11(1), 124-139. doi: 10.22059/jrur.2020.292191.1419.

Kim, A., Yang, Y., Lessmann, S., Ma, T., Sung, M.C., \& Johnson, J.E. (2020). Can deep learning predict risky retail investors? A case study in financial risk behavior forecasting. European Journal of Operational Research, 283(1), 217-234. doi: 10.1016/j.ejor.2019.11.007.

Liefner, I., \& Schiller, D. (2008). Academic capabilities in developing countries-a conceptual framework with empirical illustrations from Thailand. Research Policy, 37(2), 276-293. doi: 10. 1016/j.respol.2007.08.007.

Linton, J.D., \& Xu, W. (2021). Research on science and technological entrepreneurship education: What needs to happen next?. The Journal of Technology Transfer, 46(2), 393-406. doi: 10.1007/s10961020-09786-6.

Lundström, A., \& Stevenson, L. (2002). On the Road to Entrepreneurship Policy Swedish Foundation for Small Business Research. SE-701, 82.

Machnik-Słomka, J., \& Kordel, P. (2016). Significance of technological entrepreneurship and creativity in metallurgical enterprises. Metalurgija, 55(4), 855-858.

Maine, E. (2014). Scientist-entrepreneurs as the catalysts of NanoTechnology commercialization. Reviews in Nanoscience and Nanotechnology, 2, 1-8. doi: 10.1166/rnn.2014.1037.

Monitor, G.E. (2016). Global Entrepreneurship Monitor. Empreendedorismo no Brasil (relatório nacional). Curitiba: Instituto Brasileiro de Qualidade e Produtividade, Paraná.

Motiei, M., Moradi, M., Arabiun, A., \& Meigounpoory, M. (2019). Formulation of Technopreneurship financing polices framework. Public Policy, 4(4), 91-112. doi: 10.22059/ppolicy.2019.69719.

Navabakhsh, M., Navabakhsh, M., \& Shadnoosh, N. (2019). Discovering technology entrepreneurship opportunities in nanotechnology. Journal of Iranian Social Development Studies, 11(44), 21-42.

Naghizadeh, R., Allahy, S., \& Ranga, M. (2020). A model for NTBF creation in less developed regions based on the smart specialisation concept: the case of regions in Iran. Regional Studies, 55(3), 441-452. doi: 10.1080/00343404.2020.1736539.

Najjari, H., Didehkhani, H., Mostaghimi, M., \& Hosseini, S.M. (2021). Identifying and prioritizing the dimensions of medical tourism with emphasis on technological entrepreneurship. Journal of Health Administration, 24(1), 9-20. 
Nazarian, R., Lee, E., Siegel, B., Kuo, C., Acharya, S., \& Schmidt, J. (2021). Quantitative measurements of protein volume and concentration using hydrogel-backed nanopores. ACS Sensors, 6(3), 722-726. doi: 10.1021/acssensors.1c00284.

Nikraftar, T., \& Hosseini, E. (2016). Factors affecting entrepreneurial opportunities recognition in tourism small and medium sized enterprises. Tourism Review, 71(1), 6-17. doi: 10.1108/TR-092015-0042.

Nikraftar, T., \& Hosseini, E. (2017). The effect of prior knowledge on entrepreneurial opportunity recognition (the case study of tourism agencies participating in tourism fairs in Shiraz). Journal of Entrepreneurship Development, 9(4), 731-748. doi: 10.22059/jed.2017.61551.

Nikraftar, T., Hosseini, E., \& Moghadam, A. (2016). Identify policy implications of medical tourism in Iran. Public Policy, 2(2), 141-156. doi: 10.22059/ppolicy.2016.59235.

Palalic, R. (2017). The phenomenon of entrepreneurial leadership in gazelles and mice: A qualitative study from Bosnia and Herzegovina. World Review of Entrepreneurship, Management and Sustainable Development, 13(2-3), 211-236. doi: 10.1504/WREMSD.2017. 083026 .

Petti, C., \& Zhang, S. (2011). Factors influencing technological entrepreneurship capabilities: Towards an integrated research framework for Chinese enterprises. Journal of Technology Management in China, 6(1),7-25. doi: 10.1108/17468771111105631.

Phan, P.H., Mian, S.A., \& Lamine, W. (Eds) (2016). Technology Entrepreneurship and Business Incubation: Theory, Practice, Lessons Learned. World Scientific.

Prodan, I. (2007). A model of technological entrepreneurship. Handbook of Research on TechnoEntrepreneurship, Edward Elgar, 26-38.

Reynolds, P.D., Camp, S.M., Bygrave, W.D., Autio, E., \& Hay, M. (2002). Global Entrepreneurship Monitor Gem 2001 Summary Report. London: Kauffman Center For Entrepreneurial Leadership, 61-77.

Ribeiro, S.X., \& Nagano, M.S. (2018). Main dimensions that impact knowledge management and university-business-government collaboration in the Brazilian scenario. Revista de Gestão, 25(3), 258-273. doi: 10.1108/REGE-05-2018-0074.

Sabokro, M., Tajpour, M., \& Hosseini, E. (2018). Investigating the knowledge management effect on managers' skills improvement. International Journal of Human Capital in Urban Management, 3(2). doi: 10.10125/132.10.22034/IJHCUM.2018.02.05.

Saeeda Ardakani, S., Tajpour, M., \& Hosseini, E. (2020). The investigation of the impact of employee empowerment on knowledge sharing in post and telecommunication company (PTC) of shiraz city. Management Tomorrow, 18(60), 47-60.

Safari, F. (2018). Restrictions and legal challenges for foreign investment in the media market in Iran. Competitiveness in Emerging Markets. Springer, Cham, pp. 187-209. doi: 10.1007/978-3-31971722-7_11.

Salamzadeh, A., \& Dana, L.P. (2020). The coronavirus (COVID-19) pandemic: Challenges among Iranian startups. Journal of Small Business and Entrepreneurship, 1-24. doi: 10.1080/08276331. 2020.1821158.

Salisu, Y., \& Bakar, L.J.A. (2019). Technological capability, relational capability and firms' performance. Revista de Gestão, 27(10), 79-99. doi: 10.1108/REGE-03-2019-0040.

Salamzadeh, A., \& Kesim, H.K. (2017). The enterprising communities and startup ecosystem in Iran. Journal of Enterprising Communities: People and Places in the Global Economy, 11(4), 456-479. doi: 10.1108/JEC-07-2015-0036.

Salamzadeh, A., Tajpour, M., \& Hosseini, E. (2019). Corporate entrepreneurship in university of tehran: does human resources management matter?. International Journal of Knowledge-Based Development, 10(3), 276-292. doi: 10.1504/IJKBD.2019.103218.

Salamzadeh, A., Tajpour, M., \& Hosseini, E. (2020). Exploring the impact of social networks on entrepreneurial intention. Media Studies, 15(48), 111-124. 
REGE 29,1

98

Schaper, M. (Ed.) (2016). Making Ecopreneurs: Developing Sustainable Entrepreneurship. CRC Press.

Shane, S., \& Venkataraman, S. (2000). The promise of entrepreneurship as a field of research. Academy of Management Review, 25(1), 217-226.

Siyanbola, W.O., Aderemi, H.O., Egbetokun, A.A., \& Sanni, M. (2011). Framework for technological entrepreneurship development: Key issues and policy directions. American Journal of Industrial and Business Management, 1(1), 10.

Soleimanpour, M.R., Hosseini, S.J., \& Mirdamadi, S.M.. (2013). Factors affecting on nanotechnologybased entrepreneurship in agriculture sector of Iran. International Journal of Farming and Allied Sciences, 2 (19), 737-742.

Tajeddini, K. (2010). Effect of customer orientation and entrepreneurial orientation on innovativeness: Evidence from the hotel industry in Switzerland. Tourism Management, 31(2), 221-231. doi: 10. 1016/j.tourman.2009.02.013.

Tajpour, M. (2021). Towards the entrepreneurial university. Journal of Organizational Culture, Communications and Conflict, 25(3), 4-5.

Tajpour, M., \& Hosseini, E. (2020). The effect of intelligence and organizational culture on corporate entrepreneurship in shiraz gas compa. Human Resource Management in the Oil Industry, 12(45), 335-354.

Tajpour, M., \& Hosseini, E. (2021a). Entrepreneurial intention and the performance of digital startups: The mediating role of social media, Journal of Content, Community and Communication, 13, 2-15.

Tajpour, M., \& Hosseini, E. (2021b). Towards a creative-oriented university. Journal of Business Strategy Finance and Management, 2(1,2). doi: 10.12944/JBSFM.02.01.03.

Tajpour, M., Hosseini, E. \& Moghaddm, A., (2018). The effect of managers strategic thinking on opportunity exploitation. Scholedge International Journal of Multidisciplinary and Allied Studies, 5(2), 68-81. doi: 10.19085/journal.sijmas050602.

Tajpour, M., Hosseini, E., \& Salamzadeh, A. (2020a). The effect of innovation components on organisational performance: Case of the governorate of golestan province. International Journal of Public Sector Performance Management, 6(6), 817-830. doi: 10.1504/IJPSPM.2020.110987.

Tajpour, M., Kawamorita, H., \& Demiryurek, K. (2020b). Towards the third generation of universities with an entrepreneurial approach. International Journal of Technoentrepreneurship, 4(2), 122-133. doi: 10.1504/IJTE.2020.113927.

Tajpour, M., Hosseini, E., \& Alizadeh, R. (2021). Entrepreneurship opportunities: The effect of social entrepreneurship on the presence of Afghan immigrant youth in Iranian universities. Migration Social Entrepreneurship and Social Inclusion, 1. 261-284. doi: 10.26321/5976.020.3.261.

Weiss, C. (2020). US policy toward Scientific and technological Development in the developing countries: The Case for mutual benefit. Science, Technology, and the Issues of the Eighties. Routledge, pp. 159-189. doi: 10.4324/9780429305528-8/www.nano.ir, available at: https://news. nano.ir/wp-content/uploads/nanonews-20200905-085315.pdf.

Yan, Y., Li, J., \& Zhang, J. (2021). Protecting intellectual property in foreign subsidiaries: An internal network defense perspective. Journal of International Business Studies, 1-21. doi: 10.1057/ s41267-021-00430-5.

Zhuo, Z. (2018). Albert N. Link, Donalds, Siegel, and Mike Wright's the chicago handbook of university technology transfer and academic entrepreneurship. High Education, 75, 1125-1128. doi: 10.1007/s10734-017-0181-6.

Ziyae, B., Sadeghi, H., Nejad, M.S., \& Tajpour, M. (2021). A framework of urban entrepreneurship for women breadwinners. Foresight, 23(5), 597-609. doi: 10.1108/FS-12-2020-0137.

\section{About the authors}

Tayebeh Nikraftar is an associate professor, Faculty of Entrepreneurship, School of Entrepreneurship, University of Tehran, Tehran, Iran. Her research area is about Entrepreneurship and Tourism. Also, she 
has several publications in international journals and participated in several conferences in some countries. Tayebeh Nikraftar is the corresponding author and can be contacted at: nikraftar@ut.ac.ir

Elahe Hosseini is a PhD of Business Administration, Department of Economics, Management \& Accounting, Yazd University, Yazd, Iran. Her research interest is about organization behavior, human resource management and social and entrepreneurship activities to develop entrepreneurship in developing countries. Also, she has several publications in international journals and participated in several conferences in some countries. The title of her doctoral thesis is about employee voice of knowledge-based companies in Iran. Also, she serves as a reviewer a series of distinguished international journals such as Journal of Entrepreneurship, Business and Economics, Transnational entrepreneurship Corporations Review, SAGE Open, Academy of Strategic Management Journal, Journal of Management Information and Decision Sciences, Journal of Marketing Analytics and Journal of Iranian Public Administration Perspective.

Elham Mohammadi Brojerdi is a Graduate Master of Entrepreneurship, Faculty of Entrepreneurship, School of Entrepreneurship, University of Tehran, Tehran, Iran. Her research area is about Entrepreneurship and Marketing.

Associate editor: Aidin Salamzadeh

For instructions on how to order reprints of this article, please visit our website: 